\title{
KARAKTERISTIK UNJUK KERJA MOTOR BENSIN 4 LANGKAH DENGAN VARIASI VOLUME SILINDER DAN PERBANDINGAN KOMPRESI
}

Oleh :

\author{
ANDIK IRAWAN dan ADITYO *)
}

\begin{abstract}
ABSTRAK
Perbedaan variasi volume silinder sangat mempengaruhi unjuk kerja motor dan efiensi bahan bakar. Makalah ini menjelaskan penelitian pada sebuah motor bensin 4 langkah silinder tunggal, yaitu motor bensin CB 125 CC yang berkaitan dengan unjuk kerja motor bensin. Dalam hal ini dilakukan variasi volume

dengan memperpanjang langkah (stroke up) dengan stroke up standart, $13 \mathrm{~mm}$ dan $17 \mathrm{~mm}$ dan variasi rasio kompresi dari masing masing stroke up, yaitu ratio kompresi standart (CR; 9,4:1), rasio kompresi padat (CR; 10,1 :1) dan rasio kompresi rendah (CR; 8,2:1). Hasil penelitian ini menunjukan semakin panjang langkah maka daya efektif maksimum semakin besar. Semakin besar rasio kompresi maka torsi yang dihasilkan semakin besar. Semakin rendah nilai konsumsi bahan bakar (SFCe) maka unjuk kerja mesin semakin rendah.
\end{abstract}

Kata Kunci : Daya efektif, Rasio kompresi, SFCe.

\section{PENDAHULUAN}

Kendaraan bermotor merupakan salah satu alat transportasi, yang memerlukan engine sebagai motor penggerak mula. Motor bakar merupakan salah satu engine penggerak mula yang merubah energi kalor menjadi energi mekanik. Unjuk kerja engine sangat dipengaruhi oleh energi mekanik yang dihasilkan dari energi kalor. Perlakuan untuk meningkatkan unjuk kerja engine adalah dengan memperbaiki kualitas pembakaran bahan bakar didalam ruang bakar [1]. Peningkatan unjuk kerja engine dapat dilakukan dengan cara memperbesar diameter piston (bore up) atau memperpanjang langkah (stroke up), memperpanjang langkah sangat berpengaruh terhadap perbandingan kompresi agar menghasilkan daya dan torsi maksimal [2]. Namun memperbesar diameter piston dapat menambah resiko hingga $10 \%$ pada saat tenaga maksimal, berbeda halnya dengan memperpanjang langkah mampu meningkatkan daya dan torsi hingga $10 \%$ [3]. Peningkatan compression ratio $(C R)$ dengan campuran bahan bakar E-85 memberikan perbaikan daya engine namun tidak sebesar ignition timing [4]. Tujuan dalam penelitian ini adalah mengetahui karakteristik unjuk kerja motor bensin 4 langkah dengan variasi volume silinder dan perbandingan kompresi.

\section{METODOLOGI}

Metode dalam penelitian ini menggunakan metode experimental dengan menguji motor bensin 4 langkah menggunakan variasi perubahan standart, stroke up standart, $13 \mathrm{~mm}$, dan $17 \mathrm{~mm}$; dengan variasi rasio kompresi standart $(\mathrm{Cr}: 9,4: 1)$, rasio kompresi padat $(\mathrm{Cr}$ : $10,1: 1)$ dan rasio kompresi rendah $(\mathrm{Cr}: 8,2: 1)$ pada motor bensin 4 langkah tipe Honda CB 125CC.

Pengujian dan pengambilan data menggunakan Dynamometer. Cara pengujian sebagai berikut :

1. Pengujian kondisi mesin standart ( $\mathrm{Cr}: 9,4: 1)$ dilakukan dengan pembukaan trhotle ditahan mencapai putaran $3000 \mathrm{rpm}$, dan dibuka secara cepat hingga $9000 \mathrm{rpm}$. Selanjutnya Pencataan konsumsi bahan bakar dan hasil pengukuran menggunakan Dynamometer pada mesin kondisi standart (Cr: 9,4 : 1). Pada Volume silinder standart dilakukan pengujian ulang seperti point 1, pada rasio kompresi $\mathrm{Cr}: 10,1$ : 1. Pencatatan hasil uji dilakukan pada point ini.

2. Mengganti volume silinder standart diganti dengan Stroke up 13mm; cara pengujian Dynamometer menggunakan cara yang sama seperti point 1-2, masing - masing kompresi standart $\mathrm{Cr}: 9,4: 1$; kompresi rendah $\mathrm{Cr}: 8,2$ : 1; dan kompresi padat $\mathrm{Cr}: 10,1: 1$. Pengambilan data diambil pada point ini untuk mengetahui karakteristik unjuk kerja motor bensin 4 langkah.

3. Mengganti volume silinder standart diganti dengan Stroke up $17 \mathrm{~mm}$; cara pengujian Dynamometer menggunakan cara yang sama seperti point 1-2, masing - masing kompresi standart $\mathrm{Cr}: 9,4: 1$; kompresi rendah $\mathrm{Cr}: 8,2: 1$; dan kompresi padat $\mathrm{Cr}: 10,1: 1$.

\section{HASIL DAN PEMBAHASAN}

Momen putar (torque) merupakan gaya putar yang dihasilkan oleh poros mesin. Besarnya momen putar dapat diukur dengan menggunakan 
Dynamometer. Besarnya Momen putar dapat dirumuskan sebagai berikut:

$$
T=I . \alpha[N . m]
$$

Dengan :

$\mathrm{T}=$ Momen gaya/Torsi yang dihasilkan (N.m)

$\mathrm{I}=1 / 2 \mathrm{M} \cdot \mathrm{r}^{2}=$ inersia roller $\left(\mathrm{N} / \mathrm{m}^{2}\right)$

$\alpha=$ percepatan sudut $\left(\mathrm{rad} / \mathrm{sec}^{2}\right)$

Daya efektif merupakan daya yang dihasilkan oleh poros engkol untuk menggerakan beban. Daya efektif ini dibangkitkan oleh daya indikasi yaitu suatu daya yang dihasilkan torak. Daya efektif didapatkan dengan mengalikan Torque (T) dengan kecepatan anguler poros $(\omega)$ dengan persamaan sebagai berikut :

$$
N e=T . \omega=\frac{T .2 \cdot \pi \cdot n}{60.75}=\frac{T \cdot n}{716,2}(H P)
$$

Dengan :

$\mathrm{Ne}=$ Daya efektif $(\mathrm{HP})$

$\mathrm{T}=$ torque $(\mathrm{N} \mathrm{m})$

$\omega=$ Kec angular poros (rad. Detik $\left.{ }^{-1}\right)$

$\mathrm{n}=$ putaran poros engkol (Rpm)

Diketahui momen putar (Torsi) maksimum rata-rata tertinggi pada transmisi 3 dengan kompresi rasio (Cr) 9,4:1 pada stroke standart adalah 13.24 N.m pada 5000 Rpm, dan daya optimal sebesar $10.32 \mathrm{Hp}$ pada $6000 \mathrm{Rpm}$. Sedangkan Stroke $+13 \mathrm{~mm}$ dan $+17 \mathrm{~mm}$ dihasilkan Torsi sebesar 14.25 N.m dan 14.29 N.m pada $5500 \mathrm{Rpm}$ dengan daya $12.02 \mathrm{Hp}$ dan 13.36 Hp pada $6500 \mathrm{Rpm}$. Dari hasil yang didapat Torsi tertinggi pada $\mathrm{Cr} 9,4: 1$ pada stroke $+17 \mathrm{~mm}$. Torsi maksimum rata-rata tertinggi pada dengan kompresi rasio (Cr) 8,2:1 pada stroke standart adalah 13.13 N.m pada 5000 Rpm, dan daya optimal sebesar 9.89 Hp pada $6000 \mathrm{Rpm}$. Sedangkan Stroke $+13 \mathrm{~mm}$ dan $+17 \mathrm{~mm}$ dihasilkan Torsi sebesar 14.14 N.m dan 14.10 N.m pada $5500 \mathrm{Rpm}$ dengan daya $11.88 \mathrm{Hp}$ dan 13.03 Hp pada 6500 Rpm. Dari hasil yang didapat Torsi tertinggi pada $\mathrm{Cr} 8,2: 1$ pada transmisi 3 dengan stroke $+13 \mathrm{~mm}$.

Torsi maksimum rata-rata tertinggi pada dengan kompresi rasio $(\mathrm{Cr})$ 10,1:1 pada stroke standart adalah 13.30 N.m pada 5000 Rpm, dan daya optimal sebesar 10,41 Hp pada $6000 \mathrm{Rpm}$. Sedangkan Stroke $+13 \mathrm{~mm}$ dan $+17 \mathrm{~mm}$ dihasilkan Torsi sebesar 14.38 N.m dan 14.60 N.m pada $5500 \mathrm{Rpm}$ dan $5000 \mathrm{Rpm}$ dengan daya 12.56 Hp dan 13.59 Hp pada $6500 \mathrm{Rpm}$. Dari hasil yang didapat Torsi tertinggi pada $\mathrm{Cr}$ 10,1:1 pada transmisi 3 dengan stroke $+17 \mathrm{~mm}$. Gambar 1.a,b,c. Menunjukan Torsi (N.m) dan Daya (Hp) masing - masing Stroke pada transmisi 3.

Diketahui momen putar (Torsi) maksimum rata-rata tertinggi pada transmisi 4 dengan kompresi rasio (Cr) 9,4:1 pada stroke standart adalah 11.38 N.m pada 5500 Rpm, dan daya optimal sebesar $11.36 \mathrm{Hp}$ pada $6000 \mathrm{Rpm}$. Sedangkan Stroke $+13 \mathrm{~mm}$ dan $+17 \mathrm{~mm}$ dihasilkan Torsi sebesar 12.53 N.m dan 13.19 N.m pada $6000 \mathrm{Rpm}$ dengan daya $13.12 \mathrm{Hp}$ dan 14.89 Hp pada 7500 Rpm. Dari hasil yang didapat Torsi tertinggi pada $\mathrm{Cr} 9,4: 1$ pada stroke $+17 \mathrm{~mm}$. Torsi maksimum rata-rata tertinggi pada dengan kompresi rasio (Cr) 8,2:1 pada stroke standart adalah 11.14 N.m pada 5500 Rpm, dan daya optimal sebesar $10.88 \mathrm{Hp}$ pada $6500 \mathrm{Rpm}$. Sedangkan Stroke $+13 \mathrm{~mm}$ dan $+17 \mathrm{~mm}$ dihasilkan Torsi sebesar 12.32 N.m dan 13.03 N.m pada 6000 Rpm dengan daya $13.04 \mathrm{Hp}$ dan 14.48 Hp pada 7500 Rpm. Dari hasil yang didapat Torsi tertinggi pada $\mathrm{Cr}$ 8,2:1 pada transmisi 3 dengan stroke $+17 \mathrm{~mm}$.

Torsi maksimum rata-rata tertinggi pada dengan kompresi rasio (Cr) 10,1:1 pada stroke standart adalah 11.66 N.m pada 5500 Rpm, dan daya optimal sebesar 11,51 Hp pada $6500 \mathrm{Rpm}$. Sedangkan Stroke $+13 \mathrm{~mm}$ dan $+17 \mathrm{~mm}$ dihasilkan Torsi sebesar 12.74 N.m dan 13.43 N.m pada $6000 \mathrm{Rpm}$ dengan daya $13.64 \mathrm{Hp}$ dan 15.07 Hp pada 7500 Rpm. Dari hasil yang didapat Torsi tertinggi pada $\mathrm{Cr} 10,1: 1$ pada transmisi 4 dengan stroke $+17 \mathrm{~mm}$. Gambar 2.a,b,c. Menunjukan Torsi (N.m) dan Daya (Hp) masing - masing Stroke pada transmisi 4.

Diketahui momen putar (Torsi) maksimum rata-rata tertinggi pada transmisi 5 dengan kompresi rasio (Cr) 9,4:1 pada stroke standart adalah 10.37 N.m pada 7000 Rpm, dan daya optimal sebesar $10.98 \mathrm{Hp}$ pada $7000 \mathrm{Rpm}$. Sedangkan Stroke $+13 \mathrm{~mm}$ dan $+17 \mathrm{~mm}$ dihasilkan Torsi sebesar 11.20 N.m dan 12.33 N.m pada 7000 Rpm dengan daya $13.42 \mathrm{Hp}$ dan 16.33 Hp pada $8500 \mathrm{Rpm}$. Dari hasil yang didapat Torsi tertinggi pada $\mathrm{Cr} 9,4: 1$ pada stroke $+17 \mathrm{~mm}$. Torsi maksimum rata-rata tertinggi pada dengan kompresi rasio $(\mathrm{Cr})$ 8,2:1 pada stroke standart adalah 10.08 N.m pada 7000 Rpm, dan daya optimal sebesar $11.14 \mathrm{Hp}$ pada $7500 \mathrm{Rpm}$. Sedangkan Stroke $+13 \mathrm{~mm}$ dan $+17 \mathrm{~mm}$ dihasilkan Torsi sebesar 11.15 N.m dan 12.19 N.m pada $7000 \mathrm{Rpm}$ dengan daya $13.18 \mathrm{Hp}$ dan 16.05 Hp pada 8500 Rpm. Dari hasil yang didapat Torsi 
tertinggi pada $\mathrm{Cr} 8,2: 1$ pada transmisi 3 dengan stroke $+17 \mathrm{~mm}$.

Torsi maksimum rata-rata tertinggi pada dengan kompresi rasio $(\mathrm{Cr})$ 10,1:1 pada stroke standart adalah 10.38 N.m pada 7000 Rpm, dan daya optimal sebesar 11,58 Hp pada $7500 \mathrm{Rpm}$. Sedangkan Stroke $+13 \mathrm{~mm}$ dan $+17 \mathrm{~mm}$ dihasilkan Torsi sebesar 11.60 N.m dan 12.56 N.m pada 7000 Rpm dengan daya $13.92 \mathrm{Hp}$ dan 16.75 Hp pada 7500 Rpm. Dari hasil yang didapat Torsi tertinggi pada $\mathrm{Cr}$ 10,1:1 pada transmisi 5 dengan stroke $+17 \mathrm{~mm}$. Gambar 3.a,b,c. Menunjukan Torsi (N.m) dan Daya (Hp) masing - masing Stroke pada transmisi 5.

Konsumsi bahan bakar spesifik (SFC) menyatakan laju konsumsi bahan bakar pada suatu motor bakar torak. Pada umumnya dinyatakan dalam jumlah massa bahan bakar persatuan keluaran daya, atau dapat juga didefinisikan dengan jumlah bahan bakar yang dikonsumsi oleh motor bakar untuk menghasilkan tenaga sebesar 1 $\mathrm{Hp}$ dalam waktu satu jam. Semakin tinggi nilai SFC maka keekonomisan penggunaan bahan semakin rendah. Rumus konsumsi bahan bakar sebagai berikut :

$\mathrm{Fc}=\frac{\mathrm{b}}{\mathrm{t}} \cdot \gamma \mathrm{f} \cdot \frac{3600}{1000}\left(\mathrm{Kg}_{\mathrm{Jam}}{ }^{-1}\right)$ dan SFCe $=$

$\frac{\mathrm{FC}}{\mathrm{Ne}}\left(\mathrm{kg} \cdot \mathrm{HP}^{-1} \cdot \mathrm{jam}^{-1}\right)$

Dimana :

$\mathrm{FC}=$ konsumsi bahan bakar $(\mathrm{Kg} / \mathrm{jam})$.

$\mathrm{Ne}=$ daya efektif (HP).

$V=$ volume bahan bakar $\mathrm{t}$ detik $(\mathrm{ml})$.

$\mathrm{t}=$ waktu menghabiskan bahan bakar $V \mathrm{ml}$ (detik)

Tekanan efektif rata-rata pengamatan dari motor (break mean effective pressure) didefinisikan sebagai tekanan tetap rata - rata teoritis yang bekerja sepanjang volume langkah piston sehingga menghasilkan daya yang besarnya sama dengan daya pengamatan.

Bemp $=\frac{0.45 \cdot h p \cdot z}{A \cdot L \cdot n \cdot i \cdot 1,34}(\mathrm{Kpa})$

Dimana :

$\mathrm{A}=$ Luas penampang torak $\left(\mathrm{m}^{2}\right)$

$\mathrm{L}=$ Panjang langkah torak $(\mathrm{m})$

$\mathrm{i}=$ Jumlah silinder

$\mathrm{n}=$ Putaran mesin

$\mathrm{z}=1$ (motor 2 langkah); 2 (motor 4 langkah)
Gambar. 1a. Stroke Std, $+13 \mathrm{~mm}$ dan $17 \mathrm{~mm} \mathrm{Cr}$ pada Transmisi 3

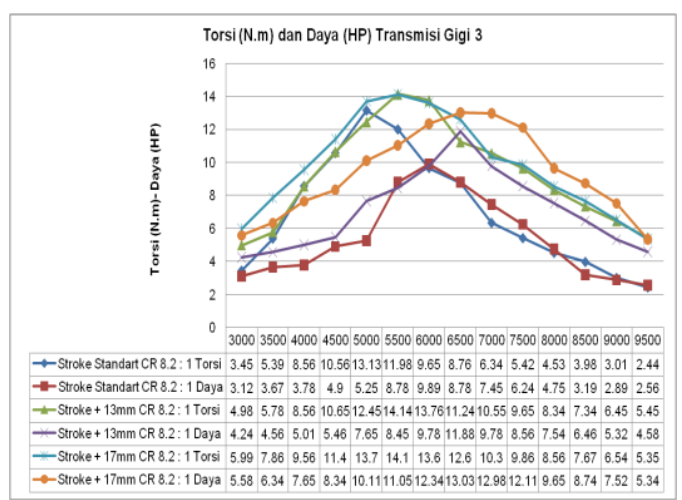

Gambar. 1b. Stroke Std, $+13 \mathrm{~mm}$ dan $17 \mathrm{~mm} \mathrm{Cr}$ 8,2:1 pada Transmisi 3

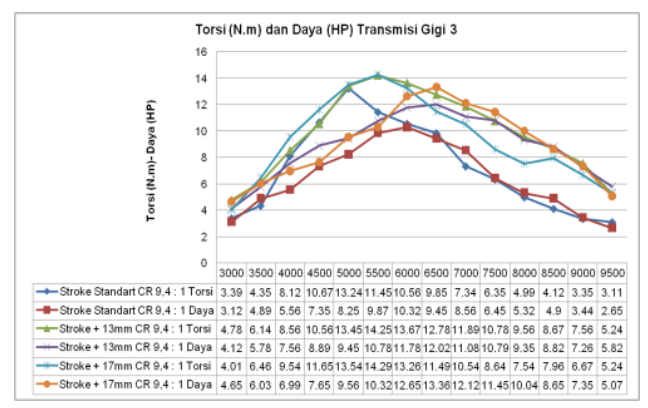

Gambar. 1c. Stroke Std, $+13 \mathrm{~mm}$ dan $17 \mathrm{~mm} \mathrm{Cr}$ 10,1:1 pada Transmisi 3

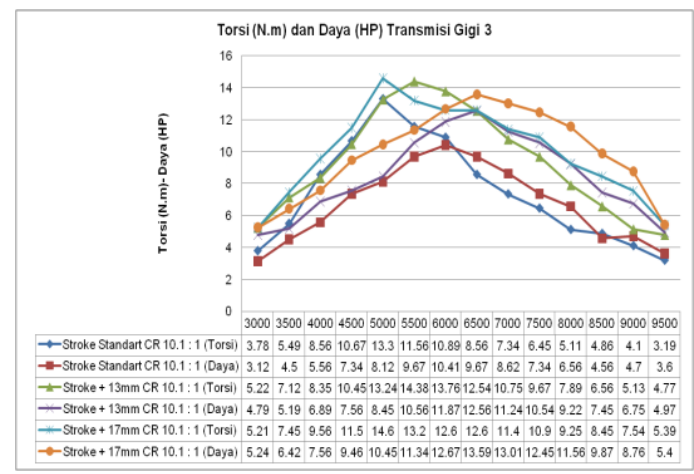


Gambar. 2a. Stroke Std, $+13 \mathrm{~mm}$ dan $17 \mathrm{~mm} \mathrm{Cr}$ 9,4:1 pada Transmisi 4

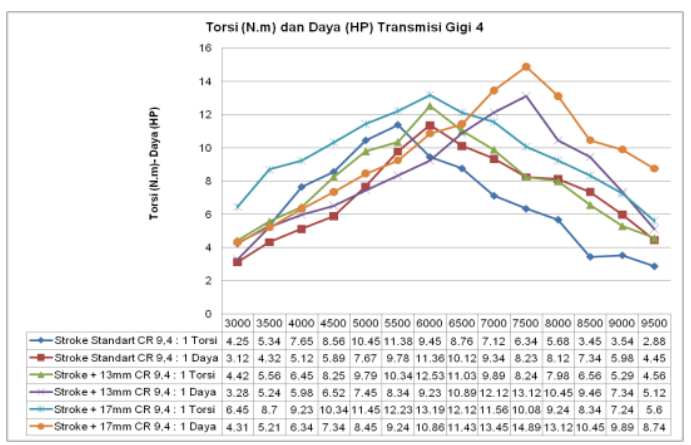

Gambar. 2b. Stroke Std, $+13 \mathrm{~mm}$ dan $17 \mathrm{~mm}$ Cr 8,2:1 pada Transmisi 4

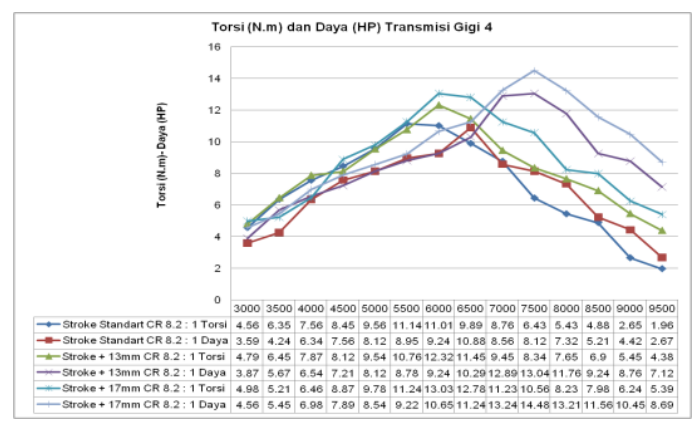

Gambar. 2c. Stroke Std, + 13mm dan $17 \mathrm{~mm}$ Cr 10,1:1 pada Transmisi 4

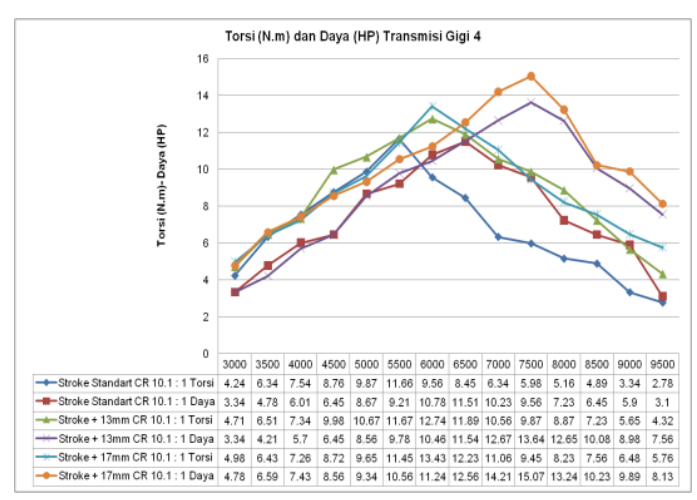

Gambar. 3a. Stroke Std, + 13mm dan $17 \mathrm{~mm}$ Cr 9,4:1 pada Transmisi 5

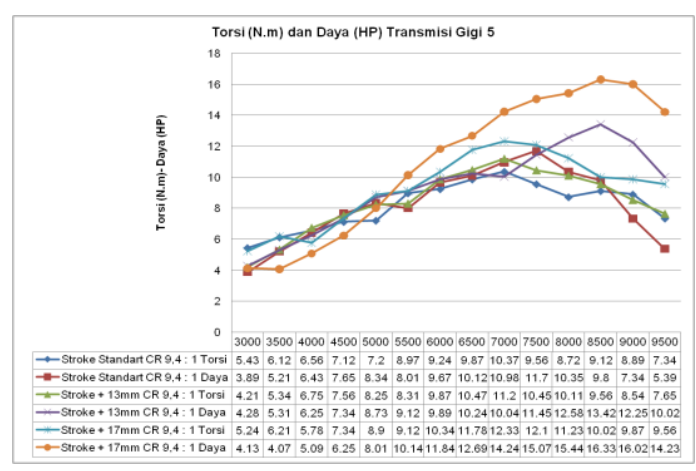

Gambar. 3b. Stroke Std, + 13mm dan $17 \mathrm{~mm}$ Cr 8,2:1 pada Transmisi 5

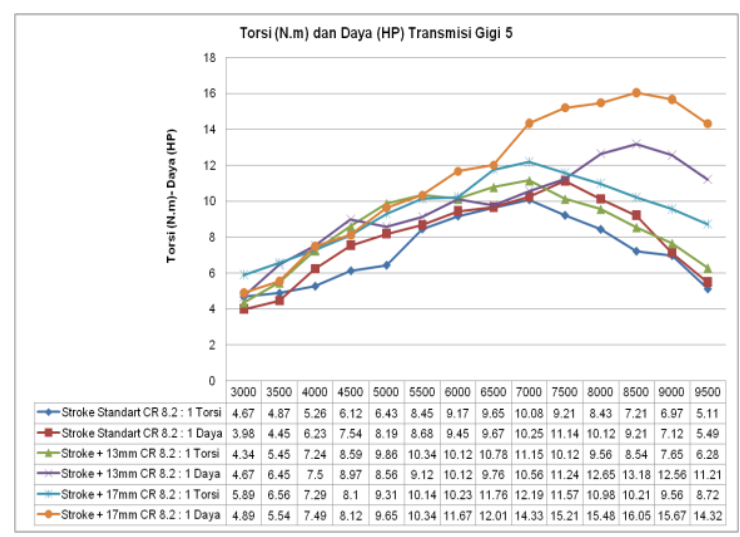

Gambar. 3c. Stroke Std, + 13mm dan $17 \mathrm{~mm} \mathrm{Cr}$ 10,1:1 pada Transmisi 5

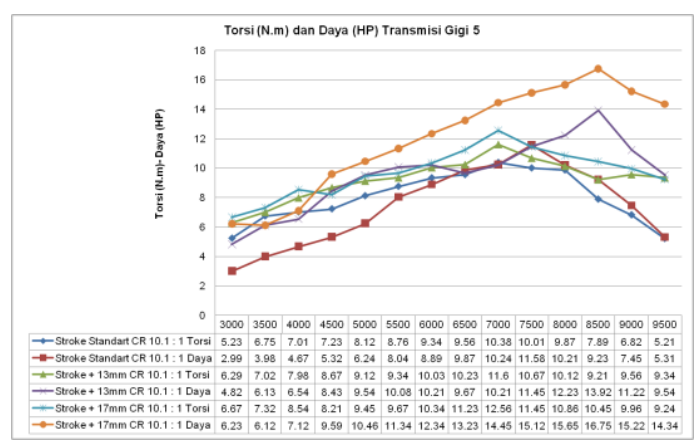


Konsumsi bahan bakar (SFC) rata - rata pada Stroke Standart dengan Cr 9,4 : 1, Cr 8,2:1; Cr 10,1:1 diantaranya 0,$21 ; 0,24 ; 0,24$. Pada Stroke +13 $\mathrm{mm}$ dan $17 \mathrm{~mm}$ pada masing - masing kompresi $\mathrm{Cr}$ 9,4:1, Cr 8,2:1 dan $\mathrm{Cr}$ 10,1:1 diantaranya 0,$19 ; 0,29 ; 0,24 ; 0,19 ; 0,18 ;$ dan 0,16 . Sedangkan BMEP berturut - turut diantaranya 11,$35 ; 8,548 ; 11,82 ; 8,96 ; 10,67 ; 11,07$; dan $11 ; 69$. SFC terendah didapatkan pada Stroke $+17 \mathrm{~mm}$ dengan $\mathrm{Cr}$ 8,2 : 1 sedangkan BMEP tertinggi didapatkan pada Stroke Standart $\mathrm{Cr}$ 10,1 : 1 . Gambar 4. Menunjukan grafik SFC dan BMEP pada tiap perbandingan kompresi.

\section{KESIMPULAN DAN SARAN}

Hasil analisa pengujian unjuk kerja motor bakar Honda CB $125 \mathrm{cc}$ dengan variabel panjang langkah (standart, stroke up $13 \mathrm{~mm}$, dan stroke up $17 \mathrm{~mm}$ ) dapat diambil sebuah kesimpulan yaitu:

1. Semakin panjang langkah, maka daya efektif maksimum rata-rata yang dihasilkan akan semakin besar. Contoh : Daya efektif ratarata pada stroke up $17 \mathrm{~mm}$ lebih besar daripada stroke standart.

2. Semakin besar rasio kompresi, maka momen putar maksimum rata-rata yang dihasilkan akan semakin besar. Contoh : Daya efektif rata-rata pada rasio kompresi 10,1: 1 lebih besar daripada rasio kompresi 8,2: 1 .

3. Semakin rendah nilai konsumsi bahan bakar spesifik maka semakin rendah konsumsi bahan bakar yang dibutuhkan untuk unjuk kerja mesin. Nilai konsumsi bahan bakar spesifik dipengaruhi oleh banyaknya volume bahan bakar yang terpakai, lama waktu pemakaian bahan bakar, dan daya yang dihasilkan. Contoh Stroke up $13 \mathrm{~mm}$ rasio kompresi 9,4:1 nilai konsumsi bahan bakarnya lebih rendah daripada stroke standart rasio kompresi 9,4:1.

4. Besar tekanan efektif rata - rata dipengaruhi oleh luas permukaan piston, panjang langkah poros engkol, daya efektif rata - rata yang dihasilkan, dan putaran mesin.

5. Motor bensin yang efisien adalah motor bensin yang menghasilkan daya efektif paling tinggi, tetapi nilai konsumsi bahan bakar spesifik yang paling rendah.

\section{SARAN}

Saran dalam penelitian ini yakni :

1. Penelitian selanjutnya dapat menggunakan variabel jenis bahan bakar dan uji emisi gas buang.

\section{UCAPAN TERIMAKASIH}

Penulis mengucapakan terimakasih kepada seluruh tim Dynotest Yamaha Central Jember yang telah memberikan fasilitas pengujian kendaraan untuk mengetahui karakteristik unjuk kerja motor bensin 4 langkah. Selain itu penulis juga mengucapakan terimakasih kepada tim Redaksi Jurnal Ilmiah Inovasi POLITEKNIK NEGERI JEMBER yang memberikan fasilitas publikasi hingga diterbitkan naskah ini.

\section{DAFTAR PUSTAKA}

[1] Badrawada,. Gede.I.G., (2008). Pengaruh Perubahan Terhadap Prestasi Mesin Motor 4 Langkah. Jurnal Forum Teknik Vol 32.

[2] Prihardintama, S., (2010). Pengaruh Durasi Noken As Terhadap Unjuk Kerja Honda Karisma Dengan Menggunakan Dua Busi. Surabaya : TA-ITS.

[3] Sulistion.F., (2010). Pengaruh Variasi Perbandingan Kompresi Ruang Bakar Pada Campuran Bahan Bakar Premium Etanol Terhadap Unjuk Kerja Motor Bensin 4 Langkah. Jember: Skripsi-UNEJ. 